Article

\title{
Postprandial Triglycerides, Flow-Mediated Dilation, and the Inflammatory Cytokine Milieu in Metabolically Healthy Obesity: A Cross-Sectional Pilot Study
}

\author{
Bryant H. Keirns ${ }^{1}{ }^{\mathbb{D}}$, Samantha M. Hart ${ }^{1}$, Christina M. Sciarrillo ${ }^{1}$, Kara L. Poindexter ${ }^{1}$, Stephen L. Clarke ${ }^{1} \mathbb{C}$ \\ and Sam R. Emerson $2, *$ (D) \\ 1 Department of Nutritional Sciences, Oklahoma State University, Stillwater, OK 74078, USA; \\ bryant.keirns@okstate.edu (B.H.K.); snielso@ostatemail.okstate.edu (S.M.H.); \\ csciarr@ostatemail.okstate.edu (C.M.S.); kpoinde@ostatemail.okstate.edu (K.L.P.); \\ stephen.clarke@okstate.edu (S.L.C.) \\ 2211 Human Sciences, Oklahoma State University, Stillwater, OK 74078, USA \\ * Correspondence: sam.emerson@okstate.edu
}

\section{check for}

updates

Citation: Keirns, B.H.; Hart, S.M.; Sciarrillo, C.M.; Poindexter, K.L.;

Clarke, S.L.; Emerson, S.R.

Postprandial Triglycerides,

Flow-Mediated Dilation, and the Inflammatory Cytokine Milieu in Metabolically Healthy Obesity: A Cross-Sectional Pilot Study. Obesities 2021, 1, 58-71. https://doi.org/ 10.3390/Obesities1010006

Academic Editor: Bruno Guigas

Received: 22 May 2021

Accepted: 7 June 2021

Published: 9 June 2021

Publisher's Note: MDPI stays neutral with regard to jurisdictional claims in published maps and institutional affiliations.

Copyright: (c) 2021 by the authors. Licensee MDPI, Basel, Switzerland. This article is an open access article distributed under the terms and conditions of the Creative Commons Attribution (CC BY) license (https:/ / creativecommons.org/licenses/by/ $4.0 /)$.

\begin{abstract}
The cardiovascular disease (CVD) risk of metabolically healthy obesity (MHO) remains controversial. We sought to further characterize the CVD risk profile in $\mathrm{MHO}$ by evaluating postprandial triglycerides, vascular function, and systemic inflammatory markers. Control individuals that were normal-weight and metabolically healthy (Con), MHO, and metabolic syndrome (MetS) were recruited ( $n=10-11$ /group). Each participant underwent an abbreviated fat tolerance test, fasting and postprandial flow-mediated dilation (FMD), and had a panel of inflammatory cytokines measured. MHO displayed postprandial triglycerides similar to those in Con and both MHO and Con had lower values than those for MetS $(p<0.01)$. Fasting FMD was lower in MHO and MetS compared to that of Con $(p<0.01)$, but during the postprandial period the vasodilatory response of MHO was similar to that while fasting $(p=0.39)$, while FMD in Con and MetS decreased after the high-fat meal ( $p$ values $<0.01$ ). MHO displayed a number of inflammatory cytokines greater than those of Con and MetS (all $p$ values $<0.05$ ), while MetS and MHO had higher TNF- $\alpha$ than did Con $(p<0.05)$. In conclusion, MHO was associated with lower fasting FMD and a greater inflammatory burden but did not suffer the same negative postprandial effects as did MetS.
\end{abstract}

Keywords: metabolically healthy obesity; postprandial triglycerides; flow-mediated dilation; inflammation; metabolic syndrome; adiposity; cardiovascular disease

\section{Introduction}

Obesity continues to represent a major public health issue and is associated with increased risk of developing cardiometabolic diseases, such as cardiovascular disease (CVD) and type 2 diabetes, as well as mortality [1-3]. Despite these associations between obesity and disease risk, it has been increasingly appreciated that individuals classified as obese are a heterogeneous population and likely have differing CVD risk. This realization of heterogeneity of disease risk has led to the concept of "metabolically healthy obesity" (MHO), which comprises anywhere from 6 to $60 \%$ of those with obesity, depending on the study population and criteria utilized to define $\mathrm{MHO}$ [4]. Most often, $\mathrm{MHO}$ refers to individuals who have a body mass index (BMI) in the obese category (BMI $\geq 30 \mathrm{~kg} / \mathrm{m}^{2}$ ) yet lack most or all criteria for metabolic syndrome (i.e., abnormal fasting glucose, HDL-C, triglycerides, blood pressure), are not treated with glucose-lowering and/or anti-hypertensive medications, and have no history of CVD [5]. This risk profile of $\mathrm{MHO}$ has been attributed to a preservation of insulin sensitivity and a greater proportion of body fat being stored subcutaneously rather than viscerally or in ectopic depots in spite of an elevated BMI [6].

Although those with MHO have a largely favorable metabolic profile based on traditional risk factors, mixed evidence suggests that $\mathrm{MHO}$ is still associated with increased 
long-term risk of developing CVD, type 2 diabetes, and mortality; in some cases, risk is similar to individuals considered metabolically unhealthy and obese [7-9]. These observations have led some to question whether $\mathrm{MHO}$ is a stable phenotype or if it is simply a transient phase on route to overt cardiometabolic disease. However, other studies have reported that the CVD and mortality risk for $\mathrm{MHO}$ is similar to lean counterparts, further contributing to the debate around this population $[10,11]$.

Given the mixed evidence and controversy surrounding the actual health status of individuals with $\mathrm{MHO}$, further characterization of their CVD risk profile is warranted. Moreover, it is possible that those with MHO may appear healthy based on the traditional risk factors by which $\mathrm{MHO}$ is typically defined, but they could be categorized as at-risk when other parameters associated with CVD risk are evaluated. Nonfasting/postprandial triglycerides is one marker that is not commonly measured, but it is an independent predictor of CVD and can be elevated despite a largely normal metabolic profile, including normal fasting triglycerides [12-14]. Additionally, the vascular health of individuals with $\mathrm{MHO}$ is not well characterized, which is implicated in the development of atherosclerosis. Lastly, while there is a clear link between inflammation and CVD risk, data on common clinical indicators of inflammation (i.e., C-reactive protein) are mixed in MHO [15-18], and most studies evaluating other inflammatory markers such as interleukin (IL)- 6 and tumor-necrosis factor (TNF)- $\alpha$ may not utilize a normal BMI control group, making it difficult to draw clear conclusions $[17,19]$. The purpose of this study was to further characterize the CVD risk profile in individuals with $\mathrm{MHO}$ by measuring postprandial triglycerides, flow-mediated dilation (FMD) as an indicator of vascular health, and a number of inflammatory mediators. We hypothesized that MHO individuals would exhibit postprandial triglycerides, FMD, and an inflammatory cytokine profile more similar to MetS than Con.

\section{Materials and Methods}

\subsection{Participants}

Thirty-one individuals aged 18-50 years $(n=10-11$ /group; 4-7 M/F) were recruited into one of three groups, healthy controls (Con), metabolically healthy obesity (MHO), and metabolic syndrome (MetS), so that MHO could be compared to low and high CVDrisk groups. Individuals were considered Con if they had a BMI of $18.5-24.9 \mathrm{~kg} / \mathrm{m}^{2}$ and $\leq 1$ metabolic syndrome criterion per the International Diabetes Federation (IDF) criteria excluding obesity (i.e., fasting triglycerides $<150 \mathrm{mg} / \mathrm{dL}$, blood pressure $<130 / 85 \mathrm{mmHg}$, fasting glucose $<100 \mathrm{mg} / \mathrm{dL}$, and HDL $>40$ and $>50 \mathrm{mg} / \mathrm{dL}$ in men and women, respectively) [20]. MHO was defined as a BMI $\geq 30 \mathrm{~kg} / \mathrm{m}^{2}$ and $\leq 1$ additional metabolic syndrome criterion, which is the most commonly utilized definition of MHO [4]. IDF criteria were used to define MetS. Additionally, participants were excluded if they had known cardiometabolic conditions (e.g., previous CVD event, type 2 diabetes), used tobacco products and/or illicit drugs, were postmenopausal, or used lipid-lowering drugs (i.e., statins, fibrates) as these drugs can lower triglycerides. All participants were free of diseases that are inflammatory in nature (e.g., rheumatoid arthritis, inflammatory bowel disease). The study was conducted according to the guidelines of the Declaration of Helsinki and approved by the Institutional Review Board of Oklahoma State University (IRB-20-339-STW, approved 9 January 2020).

\subsection{Initial Assessment}

The overall study design is depicted in Figure 1. Participants completed an initial screening visit and one study visit. Recruitment took place via mass email, snowball method, and word of mouth, primarily on the Oklahoma State University Stillwater campus. Prior to the initial screening visit, participants were asked for a self-reported BMI with inclusion criteria being $18.5-24.9$ or $>30 \mathrm{~kg} / \mathrm{m}^{2}$ to reflect normal-weight or obesity, respectively. Participants meeting BMI criteria were invited to a screening visit, where BMI was confirmed and blood pressure (Omron 5 Series BP742N; Kyoto, Japan) 
and fasting metabolic markers (Alere Cholestech; Hayward, CA, USA) were measured. Qualifying individuals were invited back for the study visit 1-2 weeks after the initial screening assessment.
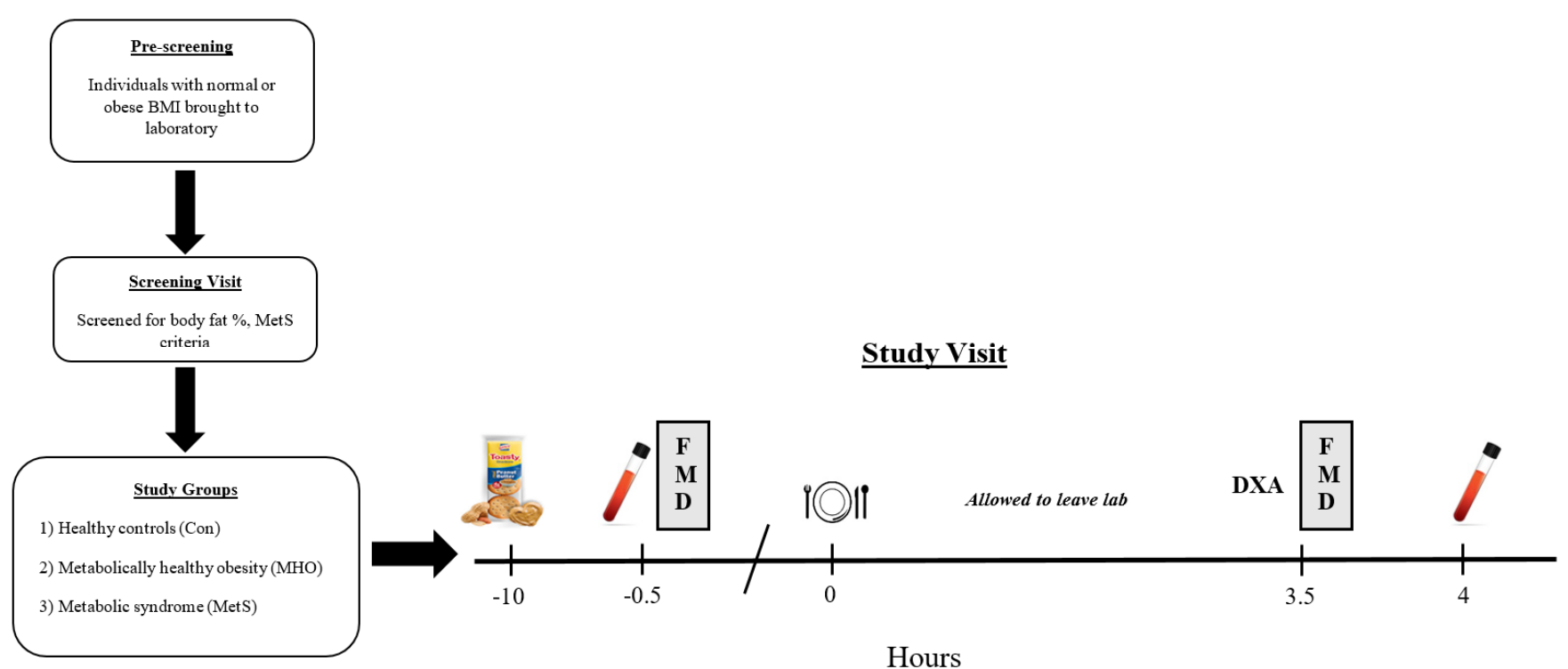

Figure 1. Overall study design. After meeting criteria for either healthy control, metabolically healthy obesity, or metabolic syndrome at the screening visit, participants were invited back for the study visit within 1-2 weeks. The hours before the study visit participants consumed the same Scheme 10. min and were then allowed to leave the lab for $\sim 3 \mathrm{~h}$ and instructed not to exercise or consume anything besides water. When participants returned, a DXA scan was performed and FMD repeated. Finally, a final blood draw was taken exactly $4 \mathrm{~h}$ after the shake was consumed.

\subsection{Fat Tolerance Test}

On the day of the study visit, participants arrived having abstained from alcohol and exercise for $24 \mathrm{~h}$. On the day before the study visit, all participants consumed the same snack (Lance peanut butter crackers; $200 \mathrm{kcal}$ ) following their normal evening meal, which initiated a $10 \mathrm{~h}$ fast before the fat tolerance test. After a fasting blood draw, a highfat shake (9 kcal $/ \mathrm{kg} ; 73 \%$ fat, $26 \% \mathrm{CHO}$ ) was administered composed of coconut cream, chocolate syrup, and pea protein powder. Participants were then allowed to leave the lab for $\sim 3 \mathrm{~h}$ with the instructions to avoid physical activity and the consumption of any food and beverage other than water. A final blood draw was taken $4 \mathrm{~h}$ after the high-fat shake was consumed, as postprandial triglycerides peak at this timepoint, on average [21]. We have previously demonstrated that this abbreviated fat tolerance test is both valid and reliable relative to more traditional and time-intensive postprandial triglyceride testing [22,23].

\subsection{Body Composition Assessment}

Body composition was assessed during the study visit using DXA (Hologic Horizon A; Marlborough, MA, USA). Whole-body DXA scans were performed prior to the final blood draw of the abbreviated fat tolerance test (Figure 1).

\subsection{Vascular Function}

Vascular function was assessed using flow-mediated dilation (FMD) in the fasted and postprandial period (Figure 1). Before beginning the FMD protocol, participants were instructed to lie in a supine position for $10 \mathrm{~min}$ in a dark, silent area to acclimate. A blood pressure cuff was then placed 2 inches from each participant's wrist. Next, a longitudinal image of the brachial artery was located using Doppler ultrasound and a $12 \mathrm{MHz}$ probe (Mindray Z5 Ultrasound System; Mindray; Mahwah, NJ, USA). After recording $2 \mathrm{~min}$ of baseline footage, the blood pressure cuff was inflated to $240 \mathrm{mmHg}$ and held for 
$4 \mathrm{~min}$ [24]. The pressure was then released, and the hyperemic response was recorded for $4 \mathrm{~min}$. Cardio Suite software (Quipu; Pisa, Italy) was used to capture pre-occlusion vessel diameter and peak vessel diameter, which were utilized to calculate the FMD \%.

\subsection{Serum Analyses}

Venous blood samples were allowed to clot and centrifuged at $2500 \times g$ for $15 \mathrm{~min}$ at $4{ }^{\circ} \mathrm{C}$ to obtain serum. Serum samples were then stored at $-80^{\circ} \mathrm{C}$ for future analyses. Screening for fasting triglycerides, HDL-C, and glucose was performed using the Cholestech LDX system (Alere; Hayward, CA, USA) reagent discs. During the study visit, baseline and $4 \mathrm{~h}$ blood samples were analyzed using the Piccolo Xpress clinical chemistry analyzer (Abbott; Chicago, IL, USA) with Lipid Panel Plus reagent discs. The panel includes direct enzymatic measurement of triglycerides, glucose, total cholesterol, HDL-C, ALT, and AST. LDL-C, non-HDL-C, and VLDL-C are calculated. To evaluate basal inflammatory status, inflammatory mediators were measured in fasting serum using the Milliplex high-sensitivity T cell panel (Millipore; Burlington, MA, USA) and were performed by Eve Technologies (Calgary, AB, Canada) per the manufacturer's instructions. Fasting insulin was measured by a commercially available, high-sensitivity ELISA (Eagle Biosciences; Amherst, NH, USA) in accordance with the manufacturer's instructions.

\subsection{Statistical Analyses}

Data were analyzed using GraphPad Prism 8 (GraphPad Prism Inc.; La Jolla, CA, USA). The Shapiro-Wilk test was used to assess if data were normally distributed. Normally distributed data were then analyzed with one-way analysis of variance (ANOVA) to determine group differences between Con, $\mathrm{MHO}$, and MetS. When data did not follow the normal distribution, the Kruskal-Wallis test was utilized. The ROUT method was used to identify outliers [25]. When $p<0.05$ for the omnibus ANOVA, Fisher's LSD was performed for post hoc analysis. Data are presented as mean \pm standard deviation and alpha $=0.05$.

\section{Results}

\subsection{Participant Characteristics}

Participant characteristics can be found in Table 1. The MHO and MetS groups had significantly higher body mass and BMI relative to those of Con ( $p$ values $<0.0001)$. When considering body composition, $\mathrm{MHO}$ and MetS had similar absolute and percent body fat and both MHO and MetS were greater than that of Con ( $p$ values $<0.01)$. Notably, MHO had lower waist circumference and less visceral fat relative to those of MetS, while both were higher than those of Con ( $p$ values $<0.0001)$. Percent lean mass was significantly lower in MHO and MetS compared to that of Con $(p<0.01)$. Absolute lean mass was lower in Con than in MetS, and MHO was similar to both groups $(p<0.05)$.

Con and MHO did not differ with respect to fasting glucose, VLDL-C, triglycerides, ALT, insulin, and homeostatic model assessment of insulin resistance (HOMA-IR), and MetS had higher values than both Con and MHO for all of those parameters (all $p$ values $<0.05)$. Further, MetS presented with lower HDL-C and greater LDL-C and non-HDL-C when compared to those of Con (all $p$ values $<0.05$ ), and MHO results were not statistically different from either group. 
Table 1. Participant and meal characteristics.

\begin{tabular}{|c|c|c|c|c|}
\hline & Con & MHO & MetS & $p$-Value \\
\hline \multicolumn{5}{|l|}{ Participant Characteristics } \\
\hline Age (years) & $27 \pm 5$ & $30 \pm 9$ & $36 \pm 7$ & 0.0514 \\
\hline Mass (kg) & $67.4 \pm 10.8^{b}$ & $96.9 \pm 11.9^{\mathrm{a}}$ & $110.7 \pm 21.2^{\mathrm{a}}$ & $<0.0001$ \\
\hline $\mathrm{BMI}\left(\mathrm{kg} / \mathrm{m}^{2}\right)$ & $22.1 \pm 1.6^{b}$ & $33.8 \pm 4.1^{\mathrm{a}}$ & $37.9 \pm 4.5^{\mathrm{a}}$ & $<0.0001$ \\
\hline WC (in) & $29.0 \pm 2.3^{c}$ & $39.1 \pm 4.2^{b}$ & $44.8 \pm 5.7^{\mathrm{a}}$ & $<0.0001$ \\
\hline Body Fat (\%) & $23.4 \pm 5.5^{b}$ & $40.2 \pm 8.2^{a}$ & $37.8 \pm 8.3^{a}$ & 0.0006 \\
\hline Body Fat (kg) & $15.8 \pm 3.7^{b}$ & $38.8 \pm 9.4^{\mathrm{a}}$ & $42.0 \pm 12.5^{\mathrm{a}}$ & $<0.0001$ \\
\hline VAT (g) & $233.4 \pm 66.0^{c}$ & $561.4 \pm 132.0^{b}$ & $795.7 \pm 244.7^{a}$ & $<0.0001$ \\
\hline Lean mass $(\%)$ & $74.0 \pm 6.0^{\mathrm{a}}$ & $57.3 \pm 8.4^{\mathrm{b}}$ & $59.8 \pm 8.0^{\mathrm{b}}$ & 0.0007 \\
\hline Lean mass (kg) & $50.1 \pm 10.3^{b}$ & $55.6 \pm 10.8^{a b}$ & $65.9 \pm 13.2^{\mathrm{a}}$ & 0.0269 \\
\hline Systolic BP (mmHg) & $108 \pm 12.0$ & $115 \pm 12$ & $122 \pm 16$ & 0.1214 \\
\hline Diastolic BP (mmHg) & $74 \pm 9$ & $82 \pm 10$ & $84 \pm 15$ & 0.1387 \\
\hline Fasting Glucose (mg/dL) & $92.4 \pm 6.7^{b}$ & $95.6 \pm 3.9^{b}$ & $103.6 \pm 12.4^{\mathrm{a}}$ & 0.0162 \\
\hline Fasting Total-C (mg/dL) & $154.6 \pm 31.6$ & $170.4 \pm 26.0$ & $180.3 \pm 33.3$ & 0.1786 \\
\hline Fasting HDL-C (mg/dL) & $66.6 \pm 11.0^{\mathrm{a}}$ & $58.1 \pm 10.5^{\mathrm{ab}}$ & $47.2 \pm 12.2^{b}$ & 0.0026 \\
\hline Fasting LDL-C (mg/dL) & $75.0 \pm 26.1^{b}$ & $93.6 \pm 21.5^{\mathrm{ab}}$ & $105.3 \pm 27.8^{a}$ & 0.0375 \\
\hline Fasting VLDL-C (mg/dL) & $12.8 \pm 3.6^{b}$ & $18.5 \pm 7.8^{b}$ & $27.9 \pm 11.8^{a}$ & 0.0015 \\
\hline Fasting Non-HDL-C (mg/dL) & $88.0 \pm 25.1^{b}$ & $112.4 \pm 21.6^{\mathrm{ab}}$ & $133.1 \pm 31.8^{\mathrm{a}}$ & 0.0027 \\
\hline Fasting TC/HDL & $2.3 \pm 0.3^{c}$ & $3.0 \pm 0.6^{\mathrm{b}}$ & $4.0 \pm 1.1^{\mathrm{a}}$ & $<0.0001$ \\
\hline $\begin{array}{l}\text { Fasting Triglycerides } \\
(\mathrm{mg} / \mathrm{dL})\end{array}$ & $64.5 \pm 18.0^{b}$ & $89.8 \pm 32.6^{b}$ & $139.1 \pm 59.1^{\mathrm{a}}$ & 0.0010 \\
\hline Fasting ALT (U/L) & $22.3 \pm 6.1^{b}$ & $27.4 \pm 6.2^{b}$ & $41.7 \pm 16.2^{\mathrm{a}}$ & 0.0008 \\
\hline Fasting AST (U/L) & $26.6 \pm 5.9$ & $23.8 \pm 4.8$ & $29.8 \pm 8.7$ & 0.1343 \\
\hline Fasting insulin (mU/L) & $1.1 \pm 0.6^{b}$ & $2.6 \pm 2.1^{b}$ & $5.5 \pm 3.6^{\mathrm{a}}$ & 0.0023 \\
\hline HOMA-IR & $0.2 \pm 0.1^{b}$ & $0.6 \pm 0.5^{b}$ & $1.5 \pm 1.1^{\mathrm{a}}$ & 0.0024 \\
\hline \multicolumn{5}{|l|}{ Fat Tolerance Test Meal } \\
\hline Total kcal & $607 \pm 97.4^{c}$ & $872.3 \pm 107.0^{b}$ & $996 \pm 191^{a}$ & $<0.0001$ \\
\hline Fat $(\mathrm{g})$ & $47.2 \pm 7.6^{c}$ & $67.9 \pm 8.3^{\mathrm{b}}$ & $77.5 \pm 14.9^{a}$ & $<0.0001$ \\
\hline Carbohydrate (g) & $31.8 \pm 5.1^{c}$ & $45.8 \pm 5.6^{b}$ & $52.3 \pm 10.0^{a}$ & $<0.0001$ \\
\hline Protein (g) & $15.2 \pm 2.4^{\mathrm{c}}$ & $21.8 \pm 2.7^{b}$ & $24.9 \pm 4.8^{\mathrm{a}}$ & $<0.0001$ \\
\hline
\end{tabular}

Data are presented as mean \pm SD. $p$-values $<0.05$ are considered statistically different. When $p$ for an omnibus 1 -way ANOVA was $<0.05$, Fisher's LSD was performed for post hoc analysis. Groups sharing the same letter are not statistically different from one another based on post hoc analyses. Abbreviations: Con healthy control; MHO metabolically healthy obesity; MetS metabolic syndrome; BMI body mass index; WC waist circumference; VAT visceral adipose tissue; HDL high density lipoprotein; LDL low density lipoprotein; VLDL very low density lipoprotein; TC total cholesterol; ALT alanine transaminase; AST aspartate aminotransferase; HOMA-IR homeostatic model assessment of insulin resistance.

\subsection{Postprandial Metabolic Parameters}

To evaluate the metabolic effects of the high-fat meal, glucose and lipid parameters at the $4 \mathrm{~h}$ time point and the absolute change from baseline to $4 \mathrm{~h}$ were analyzed (Figure 2, Table 2). Four hours after the high-fat meal, group differences in fasting HDL-C, non-HDL$\mathrm{C}$, and ALT persisted (all values $\leq 0.05$ ). Moreover, MetS displayed $141 \%$ and $63 \%$ higher triglycerides at $4 \mathrm{~h}$ compared to that of Con and MHO, respectively ( $p<0.01$; Figure $2 \mathrm{~B})$. The same pattern was observed for $4 \mathrm{~h}$ VLDL-C $(p<0.01)$. MHO did not differ from Con 
with respect to $4 \mathrm{~h}$ triglycerides and VLDL-C. When considering the absolute change in VLDL-C, MetS value was greater than that of both Con and MHO $(p<0.05)$. Similarly, MetS displayed a greater increase in triglycerides than did Con $(p=0.03)$, and MHO was similar to both groups (Figure 2C; $p$ values $>0.05$ ).
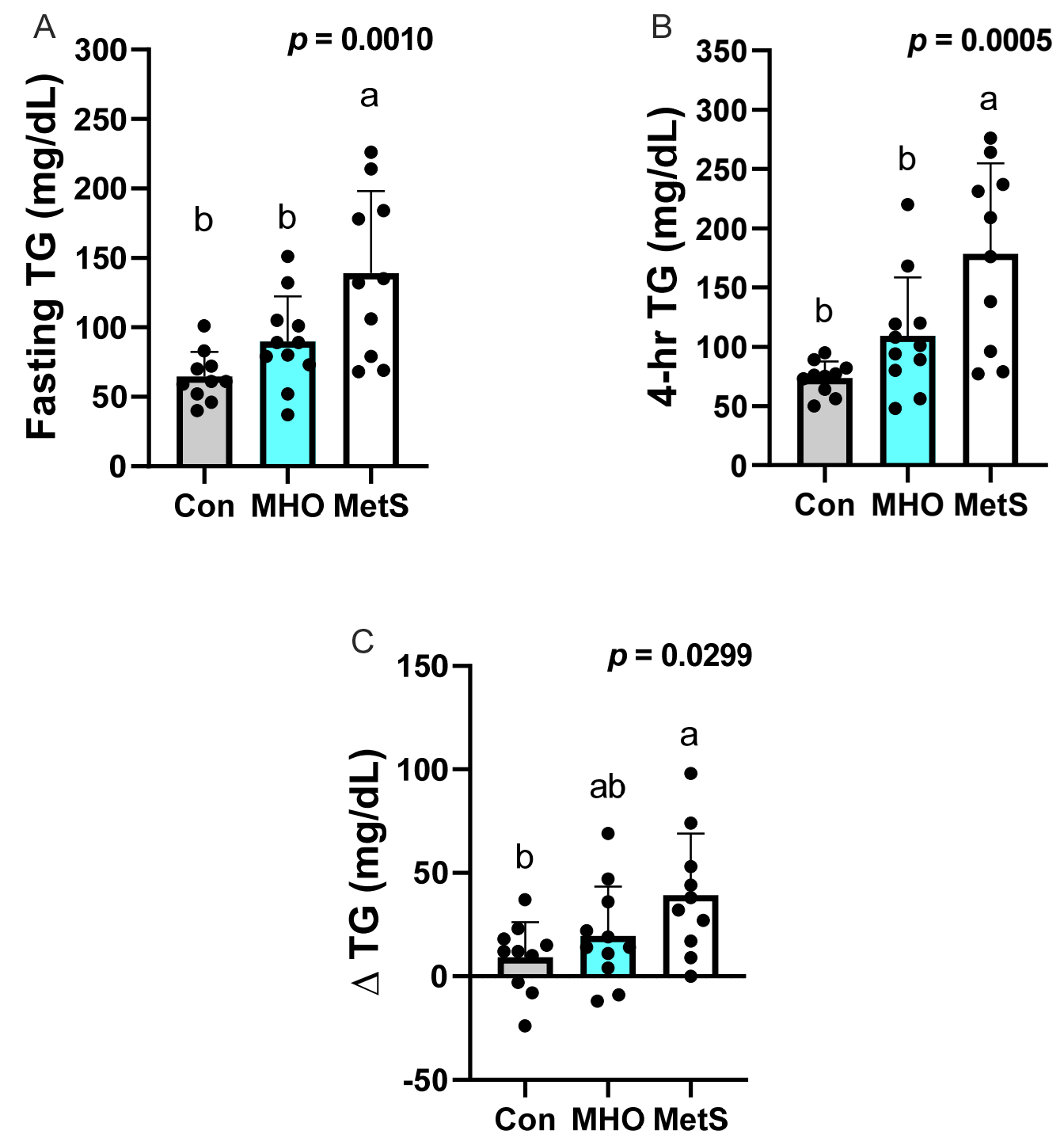

Figure 2. Fasting and postprandial triglycerides. (A) Fasting triglycerides, (B) $4 \mathrm{~h}$ triglycerides, and (C) absolute change in triglycerides. Data are presented as mean \pm SD and dots represent individual participant concentrations. Groups sharing the same letter are not statistically different from one another based on post hoc analyses. Abbreviations: Con healthy control; MHO metabolically healthy obesity; MetS metabolic syndrome; TG triglycerides.

Table 2. Postprandial metabolic outcomes.

\begin{tabular}{ccccc}
\hline & Con & MHO & MetS & $p$-Value \\
\hline Final $(\mathbf{4}$ h) & & & \\
\hline $\begin{array}{c}\text { Glucose } \\
(\mathrm{mg} / \mathrm{dL})\end{array}$ & $90.1 \pm 6.4$ & $94.2 \pm 8.7$ & $94.7 \pm 2.9$ & 0.2408 \\
\hline Total-C $(\mathrm{mg} / \mathrm{dL})$ & $157.6 \pm 30.7$ & $169.3 \pm 29.6$ & $178.0 \pm 35.9$ & 0.3433 \\
\hline HDL-C $(\mathrm{mg} / \mathrm{dL})$ & $66.5 \pm 12.3^{\mathrm{b}}$ & $55.8 \pm 12.3^{\mathrm{ab}}$ & $45.4 \pm 12.3^{\mathrm{a}}$ & 0.0027 \\
\hline LDL-C $(\mathrm{mg} / \mathrm{dL})$ & $76.3 \pm 22.3$ & $91.8 \pm 24.90$ & $96.7 \pm 26.7$ & 0.1734 \\
\hline
\end{tabular}


Table 2. Cont.

\begin{tabular}{|c|c|c|c|c|}
\hline & Con & MHO & MetS & $p$-Value \\
\hline $\begin{array}{l}\text { VLDL-C } \\
(\mathrm{mg} / \mathrm{dL})\end{array}$ & $14.7 \pm 2.8^{b}$ & $21.9 \pm 9.6^{b}$ & $35.6 \pm 15.3^{a}$ & 0.0005 \\
\hline $\begin{array}{l}\text { Non-HDL-C } \\
(\mathrm{mg} / \mathrm{dL})\end{array}$ & $90.9 \pm 23.1^{b}$ & $113.6 \pm 23.7^{a b}$ & $132.5 \pm 32.5^{\mathrm{a}}$ & 0.0063 \\
\hline TC/HDL & $2.4 \pm 0.3^{c}$ & $3.2 \pm 0.7^{b}$ & $4.1 \pm 1.2^{a}$ & $<0.0001$ \\
\hline $\begin{array}{l}\text { Triglycerides } \\
(\mathrm{mg} / \mathrm{dL})\end{array}$ & $73.7 \pm 13.9^{b}$ & $109.4 \pm 49.1^{b}$ & $178.3 \pm 76.4^{\mathrm{a}}$ & 0.0005 \\
\hline $\operatorname{ALT}(\mathrm{U} / \mathrm{L})$ & $24.5 \pm 6.4^{b}$ & $27.8 \pm 5.0^{b}$ & $42.5 \pm 17.3^{a}$ & 0.0020 \\
\hline $\begin{array}{l}\text { AST (U/L) } \\
\text { Delta }\end{array}$ & $29.0 \pm 5.9^{a b}$ & $23.2 \pm 2.9^{b}$ & $32.6 \pm 10.2^{a}$ & 0.0187 \\
\hline $\begin{array}{l}\text { Glucose } \\
(\mathrm{mg} / \mathrm{dL})\end{array}$ & $-2.3 \pm 0.9$ & $-1.4 \pm 8.5$ & $-8.9 \pm 11.0$ & 0.1324 \\
\hline Total-C (mg/dL) & $3.0 \pm 8.6$ & $-1.1 \pm 9.4$ & $-3.9 \pm 2.4$ & 0.3205 \\
\hline HDL-C (mg/dL) & $-0.1 \pm 4.1$ & $-2.3 \pm 4.0$ & $-1.8 \pm 3.0$ & 0.0980 \\
\hline LDL-C (mg/dL) & $1.3 \pm 8.4^{b}$ & $-1.7 \pm 6.9^{b}$ & $-8.6 \pm 6.0^{a}$ & 0.0093 \\
\hline $\begin{array}{l}\text { VLDL-C } \\
(\mathrm{mg} / \mathrm{dL})\end{array}$ & $1.9 \pm 3.7^{b}$ & $3.5 \pm 3.6^{\mathrm{b}}$ & $7.7 \pm 6.0^{\mathrm{a}}$ & 0.0220 \\
\hline $\begin{array}{l}\text { Non-HDL-C } \\
(\mathrm{mg} / \mathrm{dL})\end{array}$ & $2.9 \pm 6.0$ & $1.3 \pm 6.1$ & $-0.6 \pm 4.5$ & 0.3890 \\
\hline TC/HDL & $0.1 \pm 0.1$ & $0.1 \pm 0.2$ & $0.04 \pm 0.1$ & 0.3044 \\
\hline $\begin{array}{l}\text { Triglycerides } \\
\text { (mg/dL) }\end{array}$ & $9.2 \pm 17.1^{b}$ & $19.6 \pm 23.8^{a b}$ & $39.2 \pm 29.9^{a}$ & 0.0299 \\
\hline $\operatorname{ALT}(\mathrm{U} / \mathrm{L})$ & $2.2 \pm 3.5$ & $0.5 \pm 2.4$ & $1.3 \pm 1.6$ & 0.3294 \\
\hline AST (U/L) & $2.4 \pm 4.7$ & $0.5 \pm 2.8$ & $2.8 \pm 5.8$ & 0.4832 \\
\hline
\end{tabular}

Data are presented as mean \pm SD. $p$-values $<0.05$ are considered statistically different. When $p$ for an omnibus 1 -way ANOVA was $<0.05$, Fisher's LSD was performed for post hoc analysis. Groups sharing the same letter are not statistically different from one another based on post hoc analyses. Abbreviations: Con healthy control MHO metabolically healthy obesity; MetS metabolic syndrome; HDL high density lipoprotein; LDL low density lipoprotein; VLDL very low density lipoprotein; TC total cholesterol; ALT alanine transaminase; AST aspartate aminotransferase.

\subsection{Flow-Mediated Dilation}

FMD was measured as an indicator of vascular health when participants were fasted and just prior to the $4 \mathrm{~h}$ blood draw (Figure 1). Across the entire study sample, FMD decreased by $38 \%$ (from $4.0 \%$ to $2.5 \%$ ) following high-fat meal consumption $(p<0.0001$; Figure 3A). Analysis of fasting FMD revealed that Con displayed significantly greater FMD compared to that of both MHO and MetS, and MHO was similar to MetS $(p<0.01$; Figure 3B). Conversely, MHO had greater postprandial FMD than did MetS $(p<0.05)$, while Con was intermediate to MHO and MetS (Figure 3C). To follow-up on this finding, we assessed within-group changes in FMD following the high-fat meal. Interestingly, MHO had similar FMD at baseline and following the high-fat meal $(p=0.39)$, while Con and MetS both experienced a significant decrease in FMD ( $p$ values $<0.01)$. 

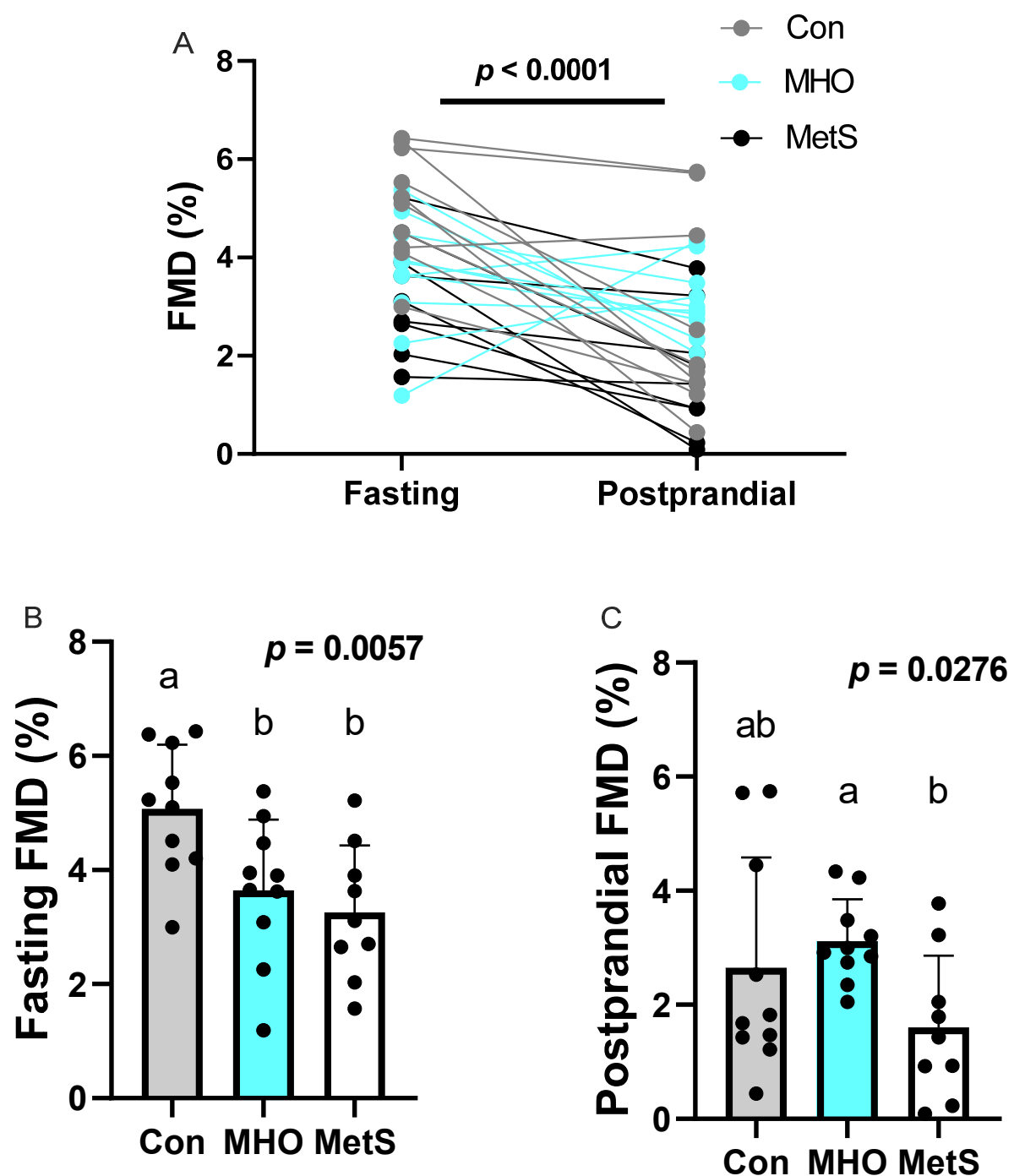

Figure 3. Fasting and postprandial flow-mediated dilation. (A) Individual changes in FMD across all groups following the high-fat meal, (B) fasting FMD, and (C) postprandial FMD. Data are presented as mean \pm SD and dots represent individual participant values. Groups sharing the same letter are not statistically different from one another based on post hoc analyses. Abbreviations: Con healthy control; MHO metabolically healthy obesity; MetS metabolic syndrome; FMD flow-mediated dilation.

\subsection{Inflammatory Mediators}

To investigate the inflammatory status of $\mathrm{MHO}$ relative to low and high-risk groups, we measured a panel of cytokines in fasting serum. Interestingly, for several cytokines generally considered pro-inflammatory (i.e., granulocyte-macrophage colony-stimulating factor (GM-CSF), IL-6, IL-8, IL-13), MHO was greater than those of both Con and MetS (all $p$ values < 0.05 ; Table 3). Somewhat similarly, IL-1 $\beta$ and IL- 5 were higher in MHO than in MetS ( $p$ values $<0.05$ ), while Con was not statistically different from either group. TNF- $\alpha$ was higher in both MHO and MetS compared to that of Con $(p<0.05)$. Other cytokines with inflammatory properties including interferon (IFN)- $\gamma$, IL-2, IL-12, and IL-17 did not differ among groups. Cytokines often regarded as anti-inflammatory (i.e., IL-10, IL-4) were also not different across study groups. 
Table 3. Serum markers of inflammation.

\begin{tabular}{|c|c|c|c|c|}
\hline & Con & MHO & MetS & $p$-Value \\
\hline $\begin{array}{l}\text { GM-CSF } \\
(\mathrm{pg} / \mathrm{mL})\end{array}$ & $19.43 \pm 18.17^{b}$ & $45.93 \pm 34.01^{\mathrm{a}}$ & $11.82 \pm 5.60^{b}$ & 0.0025 \\
\hline IFN- $\gamma(\mathrm{pg} / \mathrm{mL})$ & $3.76 \pm 2.40$ & $3.68 \pm 1.91$ & $2.97 \pm 2.18$ & 0.6526 \\
\hline IL-1 $\beta(\mathrm{pg} / \mathrm{mL})$ & $1.08 \pm 0.48^{\mathrm{ab}}$ & $1.52 \pm 0.81^{\mathrm{a}}$ & $0.71 \pm 0.39^{b}$ & 0.0249 \\
\hline $\mathrm{IL}-2(\mathrm{pg} / \mathrm{mL})$ & $2.28 \pm 1.35$ & $2.28 \pm 1.22$ & $2.03 \pm 1.73$ & 0.6490 \\
\hline IL-5 (pg/mL) & $1.38 \pm 0.62^{\mathrm{ab}}$ & $1.89 \pm 1.02^{\mathrm{a}}$ & $0.99 \pm 0.50^{b}$ & 0.0408 \\
\hline IL-6 (pg/mL) & $1.78 \pm 1.69^{\mathrm{b}}$ & $12.33 \pm 13.22^{\mathrm{a}}$ & $2.29 \pm 2.16^{b}$ & 0.0059 \\
\hline IL-8 (pg/mL) & $19.07 \pm 16.25^{b}$ & $58.70 \pm 52.35^{\mathrm{a}}$ & $10.13 \pm 4.29^{b}$ & 0.0154 \\
\hline $\begin{array}{l}\text { IL-12p70 } \\
\text { (pg/mL) }\end{array}$ & $2.65 \pm 1.36$ & $2.35 \pm 0.87$ & $2.07 \pm 1.37$ & 0.5458 \\
\hline IL-13 (pg/mL) & $5.25 \pm 4.02^{b}$ & $14.78 \pm 11.18^{\mathrm{a}}$ & $3.82 \pm 3.00^{b}$ & 0.0043 \\
\hline IL-17 (pg/mL) & $9.25 \pm 4.63$ & $10.17 \pm 5.63$ & $10.13 \pm 8.37$ & 0.9380 \\
\hline $\mathrm{TNF}-\alpha(\mathrm{pg} / \mathrm{mL})$ & $4.78 \pm 1.89^{b}$ & $7.51 \pm 3.33^{a}$ & $7.83 \pm 2.13^{a}$ & 0.0233 \\
\hline IL-4 (pg/mL) & $37.93 \pm 41.34$ & $52.07 \pm 49.02$ & $29.18 \pm 29.68$ & 0.4671 \\
\hline IL-10 (pg/mL) & $4.56 \pm 2.16$ & $4.01 \pm 1.12$ & $3.53 \pm 2.09$ & 0.4699 \\
\hline
\end{tabular}

Data are presented as mean \pm SD. $p$-values $<0.05$ are considered statistically different. When $p$ for an omnibus 1-way ANOVA was < 0.05, Fisher's LSD was performed for post hoc analysis. Groups sharing the same letter are not statistically different from one another based on post hoc analyses. Abbreviations: Con healthy control; $\mathrm{MHO}$ metabolically healthy obesity; MetS metabolic syndrome; GM-CSF granulocyte-macrophage colony-stimulating factor; IFN interferon; IL interleukin; TNF tumor necrosis factor.

\section{Discussion}

The present study investigated the extent to which those with MHO exhibited signs consistent with future cardiometabolic disease when less utilized risk factors were considered. The controversy around the health status of MHO has stemmed from the disconnect between the apparent metabolic health of $\mathrm{MHO}$ at a given moment in time when compared to mixed data suggesting this group is still at increased risk for cardiometabolic diseases (e.g., CVD and type 2 diabetes) [7-9]. To gain further insight into the cardiometabolic risk status of $\mathrm{MHO}$, we measured several cardiometabolic risk factors including postprandial triglycerides, flow-mediated dilation, and inflammatory markers, many of which have not been previously measured in MHO. In order to accomplish these aims and provide relevant context, we recruited individuals with normal BMI and $\leq 1$ metabolic syndrome criterion as healthy controls (i.e., low CVD risk) and those with metabolic syndrome (i.e., high CVD risk) to compare to $\mathrm{MHO}$, as several of the markers we measured do not have well-established reference ranges. Importantly, Con was well under the clinical cutoffs for all of the metabolic syndrome criteria, as well as all other fasting metabolic markers measured. Moreover, $\mathrm{MHO}$ was statistically similar to Con for all parameters of metabolic syndrome, fasting insulin, and HOMA-IR, and had lower waist circumference and visceral fat than MetS, indicating we captured the MHO phenotype appropriately $[16,18]$. Our MetS population also displayed clear separation from other groups for the majority of IDF criteria (i.e., fasting glucose, HDL-C, triglycerides, BMI/waist circumference).

Triglycerides after a meal (i.e., nonfasting or postprandial triglycerides) have been linked to future CVD events in several epidemiological studies [12,26,27]. Further, recent evidence has demonstrated that a subset of individuals can appear largely metabolically healthy based on fasting markers (i.e., clinically normal fasting triglycerides, HDL$\mathrm{C}$, and glucose), yet still experience a deleterious postprandial triglyceride response (i.e., $>220 \mathrm{mg} / \mathrm{dL}$ ) $[13,14,21]$. This study is the first to our knowledge to measure postprandial triglycerides after a high-fat meal challenge in those with MHO, and we hypothesized that MHO individuals may be among those who display elevated postprandial triglycerides and little other evidence of disease risk. Interestingly, we found that MHO exhibited a similar postprandial triglyceride response to Con, and that both groups had lower values than did individuals with MetS. This finding that MHO may not be among the subset of the population who has a deleterious postprandial triglyceride response is consistent with evidence that MHO status may be due to reduced liver fat and maintained insulin sensitiv- 
ity $[6,28]$. Indeed, liver steatosis is associated with higher postprandial triglycerides and contributes to hepatic insulin resistance, which impairs postprandial VLDL suppression and thereby contributes to postprandial lipemia [29,30].

Impaired vascular function generally describes the bias of blood vessels to favor vasoconstriction over vasodilation and can be attributed to a number of factors (e.g., low nitric oxide status, inflammation, oxidative stress). FMD is a common technique utilized to assess vascular function and has been shown to be inversely associated with CVD risk [31]. We observed that Con displayed significantly greater fasting FMD when compared to that of both $\mathrm{MHO}$ and MetS, and $\mathrm{MHO}$ was similar to MetS. These data are comparable to the finding that $\mathrm{MHO}$ and MetS had a similar frequency of individuals with impaired fasting FMD [32] and reports that healthy individuals have greater FMD than those with MetS [33,34]. Conversely, Sprung and colleagues [33] found that MHO had similar fasting FMD to that of non-obese controls, and those with MetS had lower FMD compared to that of both groups. To the best of our knowledge, only these two studies and the present study have measured FMD in MHO; however, other vascular assessment techniques such as forearm vascular reactivity to infusion of acetylcholine and nitroprusside have been evaluated [35]. Again, findings have been somewhat mixed, as vasodilation in MHO following acetylcholine infusion was intermediate to that of lower BMI controls and MetS, but the vasodilatory response to sodium nitroprusside was similarly lower in both $\mathrm{MHO}$ and MetS when compared to that of healthy controls. MHO has also been associated with impaired microvascular function, but to a lesser extent than metabolically unhealthy obesity [36]. Overall, while this small body of literature is inconsistent, it appears that baseline vascular function in $\mathrm{MHO}$ is at least somewhat impaired, which is in line with our data on fasting FMD.

High-fat meals have been reported to reduce FMD [37-39], leading us to measure FMD in the postprandial period as well. When analyzing the entire study sample together, we also observed a decrease in FMD following administration of the high-fat meal. After observing that postprandial FMD was similarly higher in Con and MHO versus MetS, we then measured within group changes from baseline after the high-fat meal. Interestingly, while Con and MetS experienced a significant decrease in vascular function, MHO's vasodilatory response remained relatively stable. While a postprandial drop in FMD has been previously reported, the finding that Con experienced a postprandial decrease in FMD while MHO did not is unexpected and difficult to fully explain. This pattern of results should be investigated in larger studies to be better understood, but one hypothesis based on these data could be that Con's greater baseline FMD values provided a greater potential to see a decrease following the high-fat meal, as opposed to those of MHO. MetS, on the other hand, may be advanced enough on the spectrum of cardiometabolic disease to experience a decrease in FMD despite a relatively low starting value. To our knowledge, no other studies have evaluated FMD in MHO during the postprandial period. When considering both our fasting and postprandial FMD data, it appears that, despite MHO having lower baseline FMD (similar to MetS), they were able to maintain their FMD status in spite of the high fat meal (unlike MetS).

Much like other bodies of literature on $\mathrm{MHO}$, data on the inflammatory status of $\mathrm{MHO}$ are mixed, which prompted us to perform an in-depth evaluation of circulating inflammatory mediators. In several instances, Con displayed lower markers of inflammation compared to those of groups with obesity, and the classical marker of inflammation TNF- $\alpha$ was higher in MetS compared to that of Con, both of which would be predicted $[40,41]$. Interestingly, we did not observe a difference between Con and MetS for IL-6, another well-established inflammatory marker.

Among cytokines where differences were detected in $\mathrm{MHO}$, we observed a general pattern where $\mathrm{MHO}$ values were greater than those of MetS and in most cases Con. These differences were observed in cytokines commonly viewed as inflammatory including GMCSF, IL-6, IL-8, IL-13, IL-1 $\beta$, and IL-5. Although an acute phase protein, not a cytokine, these data are similar to the report that MHO displays greater CRP than do lean individuals [42]. 
However, given that the majority of studies evaluating circulating inflammatory markers and MHO have opted to only compare MHO to metabolically unhealthy obesity (and not also a normal BMI control group), we are limited in our ability to compare/contrast our data that suggests $\mathrm{MHO}$ is associated with greater inflammatory markers than are lean controls with other studies.

One notable difference in our data versus some other reports is that MHO displayed several inflammatory mediators greater than those of MetS, and MetS had an inflammatory profile similar to that of Con. Indeed, in contrast to some of our findings, there are several reports of metabolically unhealthy obesity displaying greater CRP, IL-6, and TNF- $\alpha$ compared to those of $\mathrm{MHO}[15,17,19,43]$. However, with other inflammatory markers (i.e., IL-6, CRP), MHO values were similar to those of MetS, which highlights the variability seen with inflammatory makers in MHO [15,16,42,44]. However, we did observe higher TNF- $\alpha$ in both MHO and MetS compared to that of Con, suggesting some degree of inflammation in both obese groups. Moreover, many of the inflammatory cytokines that differed between $\mathrm{MHO}$ versus MetS and Con have not been previously measured in $\mathrm{MHO}$ (e.g., GM-CSF, IL-13, IL-5) to our knowledge. Further, while MetS has been associated with increased circulating inflammatory mediators, the IDF criteria for metabolic syndrome is not designed to capture inflammation per se, which may partially explain our findings. Moreover, a recent report has provided evidence for "adipose T cell exhaustion" and lower ex vivo cytokine secretion in samples from those with type 2 diabetes, which is similar to our results [45]. Lastly, the notion that each cytokine can simply be dichotomized as "pro-inflammatory" or "anti-inflammatory" is an incomplete view, as many cytokines can behave as pro- or anti-inflammatory depending on the context [46]. Nevertheless, although our findings were partially unexpected, this study was one of the first to characterize the inflammatory cytokine milieu of MHO compared to that of both normal-weight, healthy controls and MetS.

There were several strengths and limitations of this study. One strength is that we utilized both low and high CVD risk comparator groups, which are often lacking in studies evaluating MHO. Additionally, we assessed multiple aspects of CVD risk (i.e., dyslipidemia, vascular health, and inflammation) within the same sample, rather than focus on just one of these parameters. With respect to postprandial triglyceride assessment, our high-fat shake was scaled to body-weight, and while it is proportionally high in fat, the caloric load is similar to what an individual would reasonably consume in daily life. The present study also benefited by evaluating many inflammatory markers, rather than one or two, giving a more comprehensive picture of our sample's inflammatory state.

The present study was not without its limitations. First, there are inherent weaknesses in our cross-sectional design, although evaluating the health status of MHO at a "moment in time" is generally how this population is studied. We also had a relatively small sample size in this pilot study. Another potential limitation is that we allowed Con to have up to 1 criterion for metabolic syndrome. However, $70 \%$ of our Con group had 0 metabolic syndrome components and those that did have 1 risk factor were only slightly above the recommended thresholds, which is reflected by our group means being well below clinical cutoffs. Within our MHO group, one individual was on antihypertensive medication; however, this individual did not uniquely drive the group differences we reported with MHO. Moreover, we acknowledge that many cytokines fluctuate throughout the day and can appreciate the limitations of measuring circulating cytokines at a single time point. Although we have determined the abbreviated fat tolerance test utilized is reliable and valid compared to more traditional fat tolerance tests (i.e., serial sampling for $6-8 \mathrm{~h}$ ), it is still possible that we did not capture every participant's peak triglyceride levels with this method. The entire field of study on MHO is limited by the lack of a universal definition and our work is not immune to this. However, we did utilize the most common definition of $\mathrm{MHO}$ in order to increase the generalizability of our findings. Future mechanistic work should determine whether the inflammatory profile we observed in MHO is due to differences in adipose tissue inflammation. Additionally, others should confirm our 
observation that despite lower fasting FMD, MHO is associated with maintained vascular function in the postprandial period.

\section{Conclusions}

Overall, we report that $\mathrm{MHO}$ is associated with a number of increased inflammatory cytokines compared to those of Con and MetS, and lower fasting FMD compared to that of Con, implying $\mathrm{MHO}$ is not a benign state. However, $\mathrm{MHO}$ appeared resistant to negative effects of the high-fat meal such as decreased FMD and increased postprandial triglycerides.

Author Contributions: Conceptualization, B.H.K., S.R.E., and S.L.C. Methodology, B.H.K., S.M.H., C.M.S., S.R.E., and K.L.P., Formal analysis, B.H.K., Investigation, B.H.K., S.M.H., C.M.S., S.R.E., and K.L.P. Data curation, B.H.K. Writing-original draft preparation, B.H.K. Writing-reviewing and editing B.H.K., S.M.H., C.M.S., S.R.E., K.L.P., and S.L.C. Visualization, B.H.K., Supervision, S.R.E. Project Administration, B.H.K. and S.R.E. Funding Acquisition, B.H.K. and S.R.E. All authors have read and agreed to the published version of the manuscript.

Funding: American Society for Nutrition Mars Inc. Predoctoral Fellowship, Esther Winterfeld Summer Research Fellowship.

Institutional Review Board Statement: The study was conducted according to the guidelines of the Declaration of Helsinki and approved by the Institutional Review Board of Oklahoma State University (IRB-20-339-STW, approved 9 January 2020).

Informed Consent Statement: Written informed consent was obtained from all participants involved in the study.

Acknowledgments: We wish to thank Alejandro Penaloza-Vasquez and Jill Joyce for periodic assistance with DXA scans.

Conflicts of Interest: The authors have no conflict of interest to disclose.

\section{References}

1. Solomon, C.G.; E Manson, J. Obesity and mortality: A review of the epidemiologic data. Am. J. Clin. Nutr. 1997, 66, 1044S-1050S. [CrossRef] [PubMed]

2. Mokdad, A.H.; Ford, E.S.; Bowman, B.A.; Dietz, W.H.; Vinicor, F.; Bales, V.S.; Marks, J.S. Prevalence of Obesity, Diabetes, and Obesity-Related Health Risk Factors. JAMA 2003, 289, 76-79. [CrossRef] [PubMed]

3. Lavie, C.J.; Milani, R.V.; Ventura, H.O. Obesity and cardiovascular disease: Risk factor, paradox, and impact of weight loss. J. Am. Coll. Cardiol. 2009, 53, 1925-1932. [CrossRef] [PubMed]

4. Smith, G.I.; Mittendorfer, B.; Klein, S. Metabolically healthy obesity: Facts and fantasies. J. Clin. Investig. 2019, 129, 3978-3989. [CrossRef] [PubMed]

5. Blüher, M. Metabolically Healthy Obesity. Endocr. Rev. 2020, 41, 405-420. [CrossRef] [PubMed]

6. Stefan, N.; Häring, H.-U.; Hu, F.B.; Schulze, M.B. Metabolically healthy obesity: Epidemiology, mechanisms, and clinical implications. Lancet Diabetes Endocrinol. 2013, 1, 152-162. [CrossRef]

7. Hinnouho, G.-M.; Czernichow, S.; Dugravot, A.; Nabi, H.; Brunner, E.J.; Kivimaki, M.; Singh-Manoux, A. Metabolically healthy obesity and the risk of cardiovascular disease and type 2 diabetes: The Whitehall II cohort study. Eur. Hear. J. 2015, 36, 551-559. [CrossRef]

8. Kuk, J.L.; Ardern, C.I. Are Metabolically Normal but Obese Individuals at Lower Risk for All-Cause Mortality? Diabetes Care 2009, 32, 2297-2299. [CrossRef]

9. Choi, K.M.; Cho, H.J.; Choi, H.Y.; Yang, S.J.; Yoo, H.J.; Seo, J.A.; Kim, S.G.; Baik, S.H.; Choi, D.S.; Kim, N.H. Higher mortality in metabolically obese normal-weight people than in metabolically healthy obese subjects in elderly Koreans. Clin. Endocrinol. 2013, 79, 364-370. [CrossRef]

10. Lee, H.-J.; Choi, E.-K.; Lee, S.-H.; Kim, Y.-J.; Han, K.-D.; Oh, S. Risk of ischemic stroke in metabolically healthy obesity: A na-tionwide population-based study. PLOS ONE 2018, 13, e0195210. [CrossRef]

11. Zheng, R.; Zhou, D.; Zhu, Y. The long-term prognosis of cardiovascular disease and all-cause mortality for metabolically healthy obesity: A systematic review and meta-analysis. J. Epidemiol. Community Health 2016, 70, 1024-1031. [CrossRef]

12. Bansal, S.; Buring, J.E.; Rifai, N.; Mora, S.; Sacks, F.M.; Ridker, P.M. Fasting Compared with Nonfasting Triglycerides and Risk of Cardiovascular Events in Women. JAMA 2007, 298, 309-316. [CrossRef]

13. Koemel, N.A.; Sciarrillo, C.M.; Bode, K.B.; Dixon, M.D.; Lucas, E.A.; Jenkins, N.D.; Emerson, S.R. Postprandial Metabolism and Vascular Function: Impact of Aging and Physical Activity Level. Int. J. Sport Nutr. Exerc. Metab. 2020, 30, 1-8. [CrossRef] [PubMed] 
14. Sciarrillo, C.M.; Koemel, N.A.; Keirns, B.H.; Banks, N.F.; Rogers, E.M.; Rosenkranz, S.K.; Kurti, S.P.; Jenkins, N.D.; Emerson, S.R. Who would benefit most from postprandial lipid screening? Clin. Nutr. 2021. [CrossRef]

15. Klöting, N.; Fasshauer, M.; Dietrich, A.; Kovacs, P.; Schön, M.; Kern, M.; Stumvoll, M.; Blüher, M. Insulin-sensitive obesity. Am. J. Physiol. Metab. 2010, 299, E506-E515. [CrossRef] [PubMed]

16. Esser, N.; L'Homme, L.; De Roover, A.; Kohnen, L.; Scheen, A.J.; Moutschen, M.; Piette, J.; Legrand-Poels, S.; Paquot, N. Obesity phenotype is related to NLRP3 inflammasome activity and immunological profile of visceral adipose tissue. Diabetology 2013, 56, 2487-2497. [CrossRef]

17. Shin, M.-J.; Hyun, Y.J.; Kim, O.Y.; Kim, J.Y.; Jang, Y.; Lee, J.H. Weight loss effect on inflammation and LDL oxidation in metabolically healthy but obese (MHO) individuals: Low inflammation and LDL oxidation in MHO women. Int. J. Obes. 2006, 30, 1529-1534. [CrossRef] [PubMed]

18. Karelis, A.D.; Faraj, M.; Bastard, J.-P.; St-Pierre, D.H.; Brochu, M.; Prud'Homme, D.; Rabasa-Lhoret, R. The Metabolically Healthy but Obese Individual Presents a Favorable Inflammation Profile. J. Clin. Endocrinol. Metab. 2005, 90, 4145-4150. [CrossRef]

19. Koster, A.; Stenholm, S.; Alley, D.E.; Kim, L.J.; Simonsick, E.M.; Kanaya, A.M.; Visser, M.; Houston, D.; Nicklas, B.J.; Tylavsky, F.A.; et al. Body Fat Distribution and Inflammation Among Obese Older Adults with and Without Metabolic Syndrome. Obesity 2010, 18, 2354-2361. [CrossRef]

20. International Diabetes Federation. The IDF Consensus Worldwide Definition of the Metabolic Syndrome. International Diabetes Federation. Available online: https:/ / www.idf.org/e-library/consensus-statements / 60-idfconsensus-worldwide-definitionofthe-metabolic-syndrome (accessed on 15 March 2021).

21. Kolovou, D.G.; Mikhailidis, P.D.; Kovar, J.; Lairon, D.; Nordestgaard, G.B.; Chye Ooi, T.; Perez-Martinez, P.; Bilianou, H.; Anagnostopoulou, K.; Panotopoulos, G. Assessment and clinical relevance of non-fasting and postprandial triglycerides: An expert panel statement. Curr. Vasc. Pharmacol. 2011, 9, 258-270. [CrossRef]

22. Sciarrillo, C.M.; Koemel, N.A.; Kurti, S.P.; Emerson, S.R. Validity of an Abbreviated, Clinically Feasible Test for Postprandial Lipemia in Healthy Adults: A Randomized Cross-Over Study. Nutrition 2019, 11, 180. [CrossRef] [PubMed]

23. Dixon, M.D.; Koemel, N.A.; Sciarrillo, C.M.; Lucas, E.A.; Jenkins, N.D.; Emerson, S.R. The reliability of an abbreviated fat tolerance test: A comparison to the oral glucose tolerance test. Clin. Nutr. ESPEN 2021, 43, 428-435. [CrossRef] [PubMed]

24. Bots, M.L.; Westerink, J.H.D.M.; Rabelink, T.; De Koning, E.J. Assessment of flow-mediated vasodilatation (FMD) of the brachial artery: Effects of technical aspects of the FMD measurement on the FMD response. Eur. Hear. J. 2004, 26, 363-368. [CrossRef] [PubMed]

25. Motulsky, H.J.; Brown, R.E. Detecting outliers when fitting data with nonlinear regression-a new method based on robust nonlinear regression and the false discovery rate. BMC Bioinform. 2006, 7, 1-20. [CrossRef] [PubMed]

26. Nordestgaard, B.G.; Benn, M.; Schnohr, P.; Tybjaerg-Hansen, A. Nonfasting Triglycerides and Risk of Myocardial Infarction, Ischemic Heart Disease, and Death in Men and Women. JAMA 2007, 298, 299-308. [CrossRef] [PubMed]

27. Lindman, A.S.; Veierød, M.B.; Tverdal, A.; Pedersen, J.I.; Selmer, R. Nonfasting triglycerides and risk of cardiovascular death in men and women from the Norwegian Counties Study. Eur. J. Epidemiol. 2010, 25, 789-798. [CrossRef]

28. Stefan, N.; Kantartzis, K.; Machann, J.; Schick, F.; Thamer, C.; Rittig, K.; Balletshofer, B.; Machicao, F.; Fritsche, A.; Häring, H.-U. Identification and Characterization of Metabolically Benign Obesity in Humans. Arch. Intern. Med. 2008, 168, $1609-1616$. [CrossRef]

29. Gill, J.M.; Brown, J.C.; Bedford, D.; Wright, D.M.; Cooney, J.; A Hughes, D.; Packard, C.J.; Caslake, M.J. Hepatic production of VLDL1 but not VLDL2 is related to insulin resistance in normoglycaemic middle-aged subjects. Atherosclerosis 2004, 176, 49-56. [CrossRef]

30. Adiels, M.; Taskinen, M.-R.; Packard, C.; Caslake, M.J.; Soro-Paavonen, A.; Westerbacka, J.; Vehkavaara, S.; Häkkinen, A.; Olofsson, S.-O.; Yki-Järvinen, H.; et al. Overproduction of large VLDL particles is driven by increased liver fat content in man. Diabetology 2006, 49, 755-765. [CrossRef]

31. Ras, R.T.; Streppel, M.T.; Draijer, R.; Zock, P.L. Flow-mediated dilation and cardiovascular risk prediction: A systematic review with meta-analysis. Int. J. Cardiol. 2013, 168, 344-351. [CrossRef]

32. Temizkan, Ş.; Özderya, A.; Demir, S..; Öztürk, H.T.; Sargın, M.; Aydın, K. Endothelial Function in Distinct Phenotypes of Obesity. Turk. J. Endocrinol. Metab. 2016, 20, 117-122. [CrossRef]

33. Sprung, V.S.; Davies, K.A.B.; A Norman, J.; Thompson, A.; Mitchell, K.L.; Wilding, J.P.H.; Kemp, G.J.; Cuthbertson, D.J. Metabolic syndrome is associated with reduced flow mediated dilation independent of obesity status. Eur. J. Endocrinol. 2020, 183, 211-220. [CrossRef] [PubMed]

34. Ghiadoni, L.; Penno, G.; Giannarelli, C.; Plantinga, Y.; Bernardini, M.; Pucci, L.; Miccoli, R.; Taddei, S.; Salvetti, A.; Del Prato, S. Metabolic Syndrome and Vascular Alterations in Normotensive Subjects at Risk of Diabetes Mellitus. Hypertension 2008, 51, 440-445. [CrossRef] [PubMed]

35. Schinzari, F.; Iantorno, M.; Campia, U.; Mores, N.; Rovella, V.; Tesauro, M.; Di Daniele, N.; Cardillo, C. Vasodilator responses and endothelin-dependent vasoconstriction in metabolically healthy obesity and the metabolic syndrome. Am. J. Physiol. Metab. 2015, 309, E787-E792. [CrossRef] [PubMed]

36. Brant, L.C.C.; Wang, N.; Ojeda, F.M.; LaValley, M.; Barreto, S.M.; Benjamin, E.; Mitchell, G.F.; Vasan, R.S.; Palmisano, J.N.; Münzel, T.; et al. Relations of Metabolically Healthy and Unhealthy Obesity to Digital Vascular Function in Three Community-Based Cohorts: A Meta-Analysis. J. Am. Hear. Assoc. 2017, 6, 004199. [CrossRef] 
37. Vogel, R.A.; Corretti, M.C.; Plotnick, G.D. Effect of a Single High-Fat Meal on Endothelial Function in Healthy Subjects. Am. J. Cardiol. 1997, 79, 350-354. [CrossRef]

38. Bae, J.-H.; Bassenge, E.; Kim, K.-B.; Kim, Y.-N.; Kim, K.-S.; Lee, H.-J.; Moon, K.-C.; Lee, M.-S.; Park, K.-Y.; Schwemmer, M. Postprandial hypertriglyceridemia impairs endothelial function by enhanced oxidant stress. Atherosclerosis 2001, 155, 517-523. [CrossRef]

39. Marchesi, S.; Lupattelli, G.; Schillaci, G.; Pirro, M.; Siepi, D.; Roscini, A.R.; Pasqualini, L.; Mannarino, E. Impaired flow-mediated vasoactivity during post-prandial phase in young healthy men. Atherosclerosis 2000, 153, 397-402. [CrossRef]

40. Mohammadi, M.; Gozashti, M.; Aghadavood, M.; Mehdizadeh, M.R.; Hayatbakhsh, M.M. Clinical Significance of Serum IL-6 and TNF- $\alpha$ Levels in Patients with Metabolic Syndrome. Rep. Biochem. Mol. Biol. 2017, 6, 74-79. [PubMed]

41. Hotamisligil, G.S. Inflammation and metabolic disorders. Nature 2006, 444, 860-867. [CrossRef]

42. Iglesias Molli, A.E.; Penas Steinhardt, A.; López, A.P.; González, C.D.; Vilarino, J.; Frechtel, G.D.; Cerrone, G.E. Metabolically healthy obese individuals present similar chronic inflammation level but less insulin-resistance than obese individuals with metabolic syndrome. PLoS ONE 2017, 12, e0190528. [CrossRef]

43. Fabbrini, E.; Cella, M.; Mccartney, S.A.; Fuchs, A.; Abumrad, N.A.; Pietka, T.A.; Chen, Z.; Finck, B.N.; Han, D.H.; Magkos, F.; et al. Association Between Specific Adipose Tissue CD4+ T-Cell Populations and Insulin Resistance in Obese Individuals. Gastroenterology 2013, 145, 366-374.e3. [CrossRef] [PubMed]

44. Kouvari, M.; Panagiotakos, D.B.; Yannakoulia, M.; Georgousopoulou, E.; Critselis, E.; Chrysohoou, C.; Tousoulis, D.; Pitsavos, C.; The ATTICA Study Investigators. Transition from metabolically benign to metabolically unhealthy obesity and 10-year cardiovascular disease incidence: The ATTICA cohort study. Metabolism 2019, 93, 18-24. [CrossRef]

45. Porsche, C.E.; Delproposto, J.B.; Geletka, L.; O’Rourke, R.; Lumeng, C.N. Obesity results in adipose tissue T cell exhaustion. JCI Insight 2021, 6, 6. [CrossRef] [PubMed]

46. Cavaillon, J.M. Pro- versus anti-inflammatory cytokines: Myth or reality. Cell. Mol. Boil. 2001, 47, 695-702. 